Article

\title{
A New Methodology for Smoothing Power Peaks Produced by Electricity Demand and a Hydrokinetic Turbine for a Household Load on Grid Using Supercapacitors
}

\author{
Paul Arévalo (D), Marcos Tostado-Véliz * (D) and Francisco Jurado (D) \\ Department of Electrical Engineering, University of Jaen, 23071 Jaen, Spain; wpac0001@red.ujaen.es (P.A.); \\ fjurado@ujaen.es (F.J.) \\ * Correspondence: mtostado@ujaen.es
}

\section{check for} updates

Citation: Arévalo, P.; Tostado-Véliz, M.; Jurado, F. A New Methodology for Smoothing Power Peaks Produced by Electricity Demand and a

Hydrokinetic Turbine for a

Household Load on Grid Using Supercapacitors. World Electr. Veh. J 2021, 12, 235. https://doi.org/ 10.3390/wevj12040235

Academic Editors: Zonghai Chen and Joeri Van Mierlo

Received: 30 September 2021 Accepted: 10 November 2021 Published: 11 November 2021

Publisher's Note: MDPI stays neutral with regard to jurisdictional claims in published maps and institutional affiliations.

Copyright: (c) 2021 by the authors. Licensee MDPI, Basel, Switzerland. This article is an open access article distributed under the terms and conditions of the Creative Commons Attribution (CC BY) license (https:/ / creativecommons.org/licenses/by/ $4.0 /)$.

\begin{abstract}
The power fluctuations produced by electric vehicles represent a drawback in large-scale residential applications. In addition to that, short power peaks could pose a risk to the stability of the electrical grid. For this reason, this study presents a feasibility analysis for a residential system composed of electric vehicle chargers. The objective is focused on smoothing the power fluctuations produced by the charge by a supercapacitor through adequate energy control; in addition, selfconsumption is analyzed. Data sampling intervals are also analyzed; the modeling was performed in Matlab software. The results show that there are errors of up to $9 \%$ if the data are measured at different sampling intervals. On the other hand, if the supercapacitor is considered, the system saves $59.87 \%$ of the energy purchased from the utility grid per day, and the self-consumption of electricity by prosumers can increase up to $73 \%$. Finally, the hydrokinetic/supercapacitor/grid system would save up to 489.1 USD/year in the cost of purchasing electricity from the grid and would increase by 492.75 USD/year for the sale electricity.
\end{abstract}

Keywords: supercapacitor; hydrokinetic energy; power smoothing; self-consumption; renewable system; electric vehicles

\section{Introduction}

\subsection{Motivation and Incitement}

The generation of electricity with alternative sources is increasing, from large wind farms, solar farms and hydroelectric plants to small generators for residential use; the last are known as distributed generation and are able to reduce losses through transmission and distribution [1]. The main challenge of distributed generation is the stability of renewable systems based on stochastic resources on grid, which, on a large scale, can cause serious problems of voltage or frequency variations that could cause a collapse of the electrical power system [2]. To solve this problem, several studies of the literature reviewed propose various control systems based on high-cost intelligent controllers or reduce renewable generation to maximum limits established by the regulations in each country [3]. In this paper, an economical and simple solution is presented when using supercapacitors (SCs) to smooth the power peaks of a hydrokinetic turbine and a residential load on grid, including the demand for an electric vehicle that is charged in off-peak hours. In addition, the self-consumption produced by the renewable source and the SC is studied. All analyses are compared under different data-sampling intervals for the technical and economic results presented.

\subsection{Related Works}

In the literature, various authors have explored various solutions for power smoothing in renewable systems, taking advantage of various storage technologies, such as batteries and SCs [4]. In this regard, the authors in Reference [5] developed a control scheme 
for a hybrid storage system comprising SC-batteries, by which the power fluctuations produced by wind farms can be reduced, thus improving the lifespan of batteries. Similarly, Jayalakshmi et al. developed, in Reference [6], a grid-side control for peak reduction of hybrid renewable systems formed by photovoltaic (PV) panels and wind turbines (WTs). In this case, the power smoothing was achieved by optimally controlling a storage system formed by SC banks. In Reference [7], the authors developed an energy management program based on nonlinear predictive control by which the grid-side voltage is kept almost constant, thus reducing power peaks and large fluctuations. Other particular aspects of each storage technology were highlighted, noting that a hybrid storage facility formed by SCs and batteries is more promising than a solution based on each technology separately. In Reference [8], the authors present a statistical approach to develop the capacity of a hybrid energy storage system (HESS), using the Monte Carlo simulation. HESS sizing results are set at different levels of cumulative probability. Then, in Reference [9], they analyzed a hybrid configuration at the wind turbine level of an energy storage system to limit power ramp rates and apply power smoothing; the results showed that significant improvements can be made by using HESS. In this sense, SCs can contribute to expand the lifetime of batteries by absorbing high peaks, because of their high power rate, and also to provide inertia to the grid. In Reference [10], a control is proposed to manage the energy exchange between batteries and supercapacitors based on the photovoltaic power curves. This innovative contribution not only reduces the voltage levels in the battery and therefore increases its service life, but also provides a constant injection of energy into the grid for a defined time interval. Similarly, in Reference [11], an inclusive review of hybrid energy storage consisting of batteries and supercapacitors is presented. The results show that supercapacitors can reduce battery charging ramps under power peaks. Storage systems based on SCs may also find applicability in hydrokinetic systems, since such generators in particular have similar dynamic behavior to that of WTs [12], where extensive simulations have been performed to demonstrate the capacity of SCs to reduce power fluctuations of renewable systems. In Reference [13], the authors proposed a management system based on polynomial control for an off-grid microgrid comprising a hybrid storage system, renewable generators and diesel engines, demonstrating that the developed control program is able to reduce power fluctuations notably, besides reducing the storage capacity. Similarly, González et al. developed, in Reference [14], three different control strategies for PV arrays with storage systems composed by SCs.

SC banks are able to act rapidly, being so necessary to use high-resolution data, as pointed out in Reference [15], where the authors explained the advantage of using high-resolution measurements in control schemes for SCs. This strategy allowed the authors to reduce the storage sizing, because of the accurateness of the results obtained. In Reference [16], an optimization of photovoltaic household prosumers based on batteries/supercapacitors is presented that provides self-consumption and reserve of frequency containment according to the influence of the granularity of the temporal data, the modeling optimizes the size and the management of the energy from photovoltaic household consumers. In Reference [17], the authors performed a multi-objective optimization of the isolated photovoltaic battery system. An optimization and sizing of a photovoltaic system with a supercapacitor to improve self-consumption is presented in Reference [18]; the low resolution of time load generates up to $37 \%$ error during the analysis. These conclusions were strengthened in Reference [19] through numerical simulations in a microgrid layout with high renewable penetration. In this last reference, the authors also highlighted the importance of storage systems to reduce power fluctuations, along with increasing the efficiency of a household system. Similarly, numerical results presented in Reference [20] showed that self-consumption of a residential system can be boosted up by $51 \%$ by installing batteries, in comparison with the solution in which only PV panels are installed.

Other references were devoted on studying the impact of storage facilities in off-grid systems [21], concluding that the behavior in both cases was similar, notably reducing the 
cost of energy. Nevertheless, the proper sizing of grid components is of vital importance, as pointed out in Reference [22], where the authors highlighted that, for increasing selfconsumption, it is preferable to increase the capacity of storage rather than repower the PV arrays. In addition, storage systems may help to improve various energy quality indexes, such as flicker and voltage sags. This aspect was analyzed in Reference [23], where the authors performed various simulations in a stochastic framework for a storage system composed by batteries, through which they demonstrated that, by properly controlling the storage system, the self-consumption can be improved while primary frequency control is provided complementarily.

Along with the most typical renewable-based configurations based on PV arrays and WTs, power fluctuations issues appear with other technologies, such as hydrokinetic turbines (HKTs), which may provoke power fluctuations because the variability of river speed and swell or turbulences [24]. In this sense, SCs can help to eliminate power disturbances caused by HKTs, as demonstrated in Reference [25]. John et al. proposed, in Reference [26], an integrated HKT-PV system supported by batteries for energy supplying of remote communities. In Reference [27], the authors analyzed a PV-wind-biogas-syngashydrokinetic-batteries layout, for energy provision of an academic municipality in the East District of Sikkim, India, reducing the cost of energy to $0.09 \mathrm{USD} / \mathrm{kWh}$. Hydrokinetic generation may improve the efficiency of on-grid houses, as demonstrated by Tani et al. in Reference [14], where a day-ahead scheduling control for HKTs was proposed, by which the cost of operation can be reduced maximizing the energy sold to the grid. Finally, it is worth noting that despite hydrokinetic technology is an emerging renewable generation concept, its similarity to wind generation enable the possibility of reusing some existing control schemes of WTs for HKTs, making so easier the implantation of hydrokinetic generation throughout the world [28].

\subsection{Contributions and Paper Organization}

In the literature reviewed in this paper, the vast majority studied the smoothing of power peaks of wind farms and photovoltaic farms; the study of self-consumption and the resolution of the data sampling is carried out entirely from the latter mentioned. Similar studies, such as Reference [25], are found in the literature, where they present the smoothing of HKT power peaks; however, in Reference [25], the authors did not make a comparison of different data-sampling intervals, nor did they analyze self-consumption. For this context, this paper further explores the capability of SCs to reduce power fluctuations caused by some emerging appliances, such as electric vehicles (EVs). It is assumed that the EV is connected directly at home. In this sense, an SC bank is integrated into an on-grid system with high penetration of hydrokinetic energy. Thereby, the capacity of SCs to jointly reduce the fluctuations caused by loads and HKTs was studied. This work is also devoted to analyzing the influence of SC banks in increasing the self-consumption rate of the system. To this end, the system was studied with various time intervals in order to determine the influence of this aspect in final results. Finally, an economical study was performed in order to discern the economic viability of the proposed system and the considered energy control scheme.

In the rest of this paper, Section 2 describes the methodology that was followed in the study. Section 3 provides and comments upon the extensive results obtained in the simulations. Finally, this paper is concluded with Section 4.

\section{Methodology}

This paper presents a feasibility study of a renewable system on grid (HKT/SC). The input variables, namely the river speed, the electricity demand and the cost of the components, were measured under different sampling intervals (1, 15, 30 and $60 \mathrm{~min}$ ). Subsequently, an energy control is proposed for each case, smoothing the power peaks produced by HKT and by customer load through an SC. The renewable source, together with the ESS, offers self-consumption to prosumers, e.g., the surplus electricity to the grid 
and, in some cases the purchase of electricity from the grid. These parameters were compared through simulations in Matlab software based on mathematical models presented in this paper. Finally, the technical and economic results of the proposed study are presented. Comparisons of the system were made with SC and without it, for all sampling intervals. Figure 1 shows a diagram of the methodology presented.

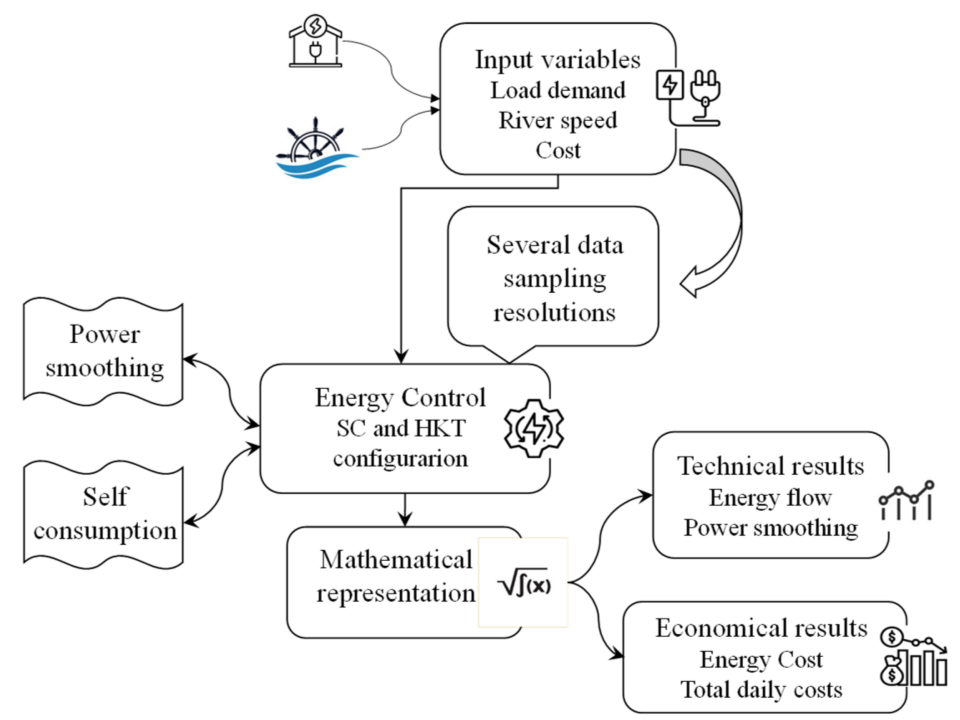

Figure 1. Representative diagram of the proposed methodology.

\subsection{Background}

\subsubsection{Load Demand}

The electrical consumption of a typical household on a grid located in the south of Ecuador, near the city of Cuenca, was measured. It is considered to be a slow charging station for an EV with a peak power of $6 \mathrm{~kW}$, including residential consumption; the daily load curve is shown in Figure 2 [29]. It is possible to identify two considerable load peaks: The first peak, which occurs at around 8:00 p.m., has a power of around $3 \mathrm{~kW}$ and corresponds to the consumption of the prosumers; the EV load was chosen through a consumption programming in off-peak hours, starting to recharge the EV from 10:00 p.m. The second power peak reaches $6 \mathrm{~kW}$ at approximately 11:00 p.m. The real values were measured by hourly energy meters.

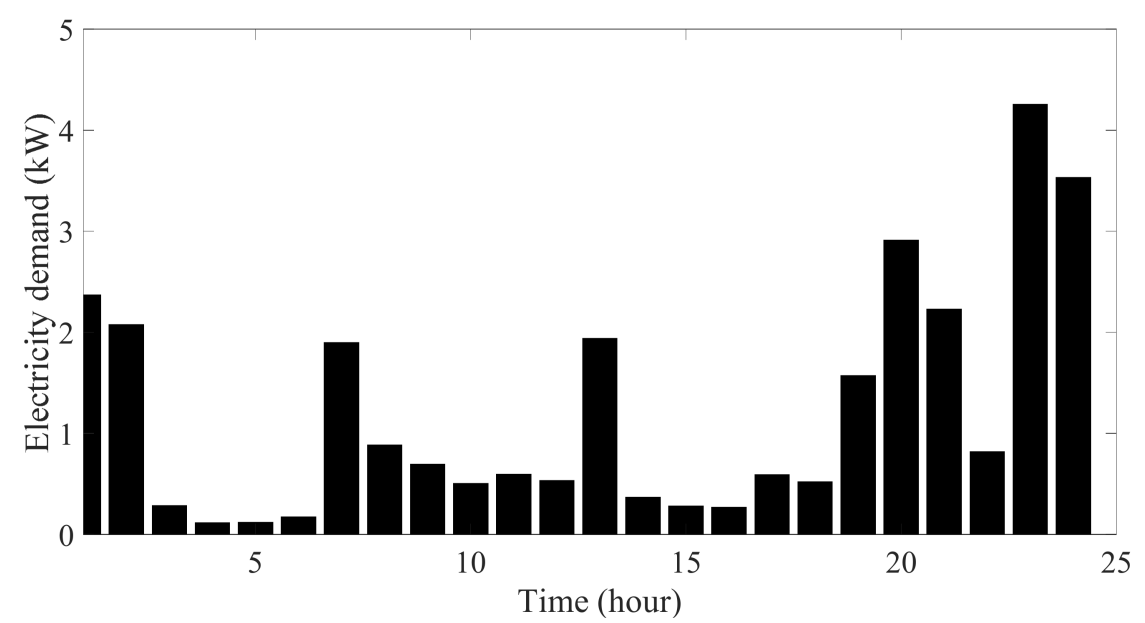

Figure 2. Daily demand curve-daily hourly values considering the load of an EV. 
By increasing the data sampling rate, the power peaks are evident. Figure 3 shows the demand curve measured at different sampling intervals; if the time interval is longer (values measured every $60 \mathrm{~min}$ ), the power peaks are not noticeable.

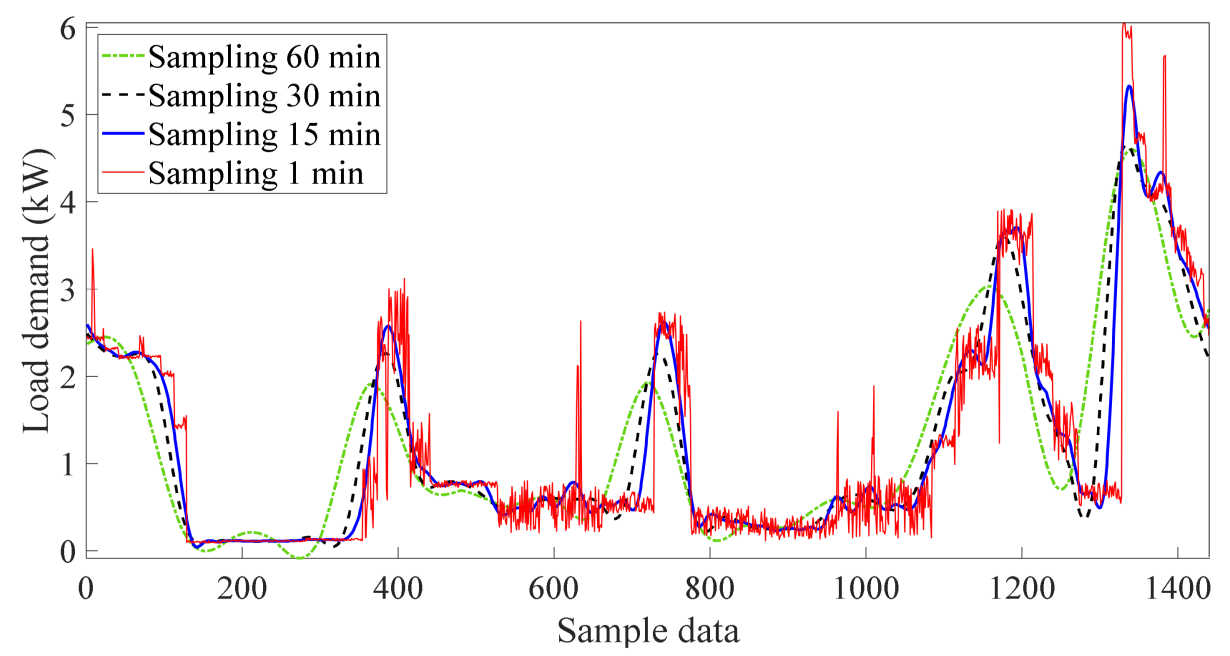

Figure 3. Daily electricity demand curve—values measured at different sampling intervals.

\subsubsection{River Speed}

The average daily speed of the Paute River, Ecuador, is $1.85 \mathrm{~m} / \mathrm{s}$ and was measured by means of a hydrological station installed on the river [30]. These data are used as an example of the variation in the river speed during a 24-h interval, and they are representative of a daily cycle. Hourly measurements show a minimum speed of $1.73 \mathrm{~m} / \mathrm{s}$ and a maximum speed of $2.02 \mathrm{~m} / \mathrm{s}$ during a day chosen at random, as shown in Figure 4. Similarly, greater variations in river speed are observed while the sampling rate is higher (values measured every $1 \mathrm{~min}$ ), resembling the real behavior of the system, as shown in Figure 5.

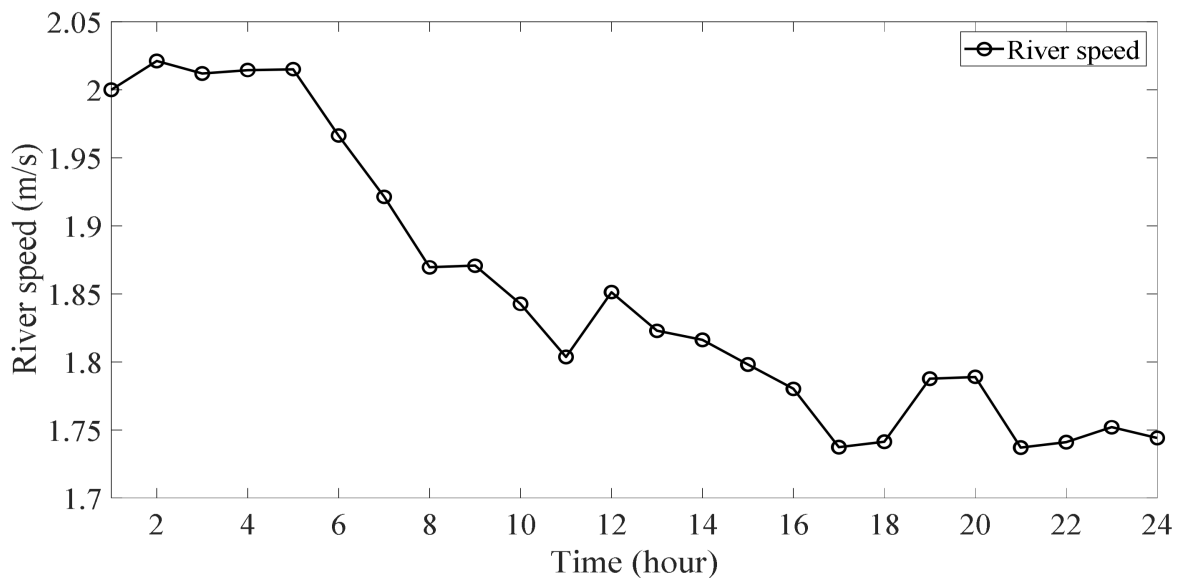

Figure 4. River speed-hourly average values measured during a day. 


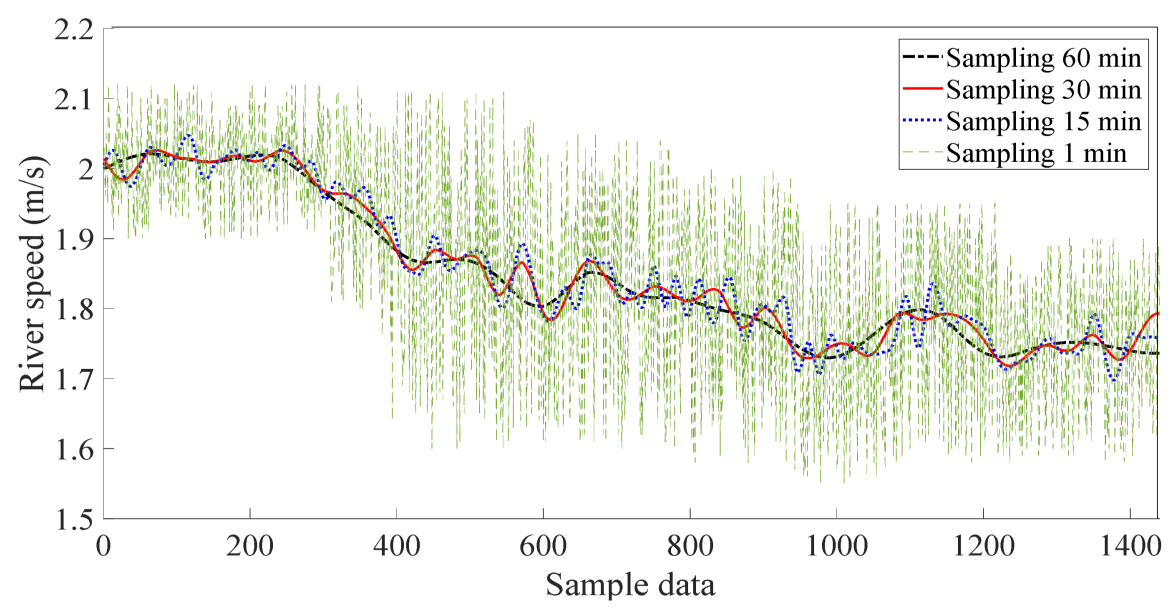

Figure 5. River speed—values measured at different sampling intervals.

\subsection{Energy Control}

The energy control that is proposed has, as a priority, to supply the demand (household $+\mathrm{EV})$ with as much renewable energy as possible. In order to measure this amount of energy consumed, self-consumption is defined as the energy generated by HKT and consumed by users. If this parameter increases, the energy purchased from the utility grid will be less. To achieve this aim, the SC has the goal of storing energy to supply the demand if HKT is not able to generate electricity; at the same time, the SC smooths the power peaks produced by HKT and the load. Figure 6 graphically explains the proposed control algorithm in each given condition. $P_{\text {load }}$ represents the residential electricity demand, including the EV; $P_{H K T}$ is the electric output power of HKT; $P_{S C}$ is the electric output power of SC; $P_{\text {from-grid }}$ represents the surplus electricity produced by HKT sent to the utility grid; and $P_{\text {to-grid }}$ represents the unmet load by $\mathrm{HKT}$, it is the electricity purchased from the utility grid; $S O C_{S C}$ is the state of charge in the SC.

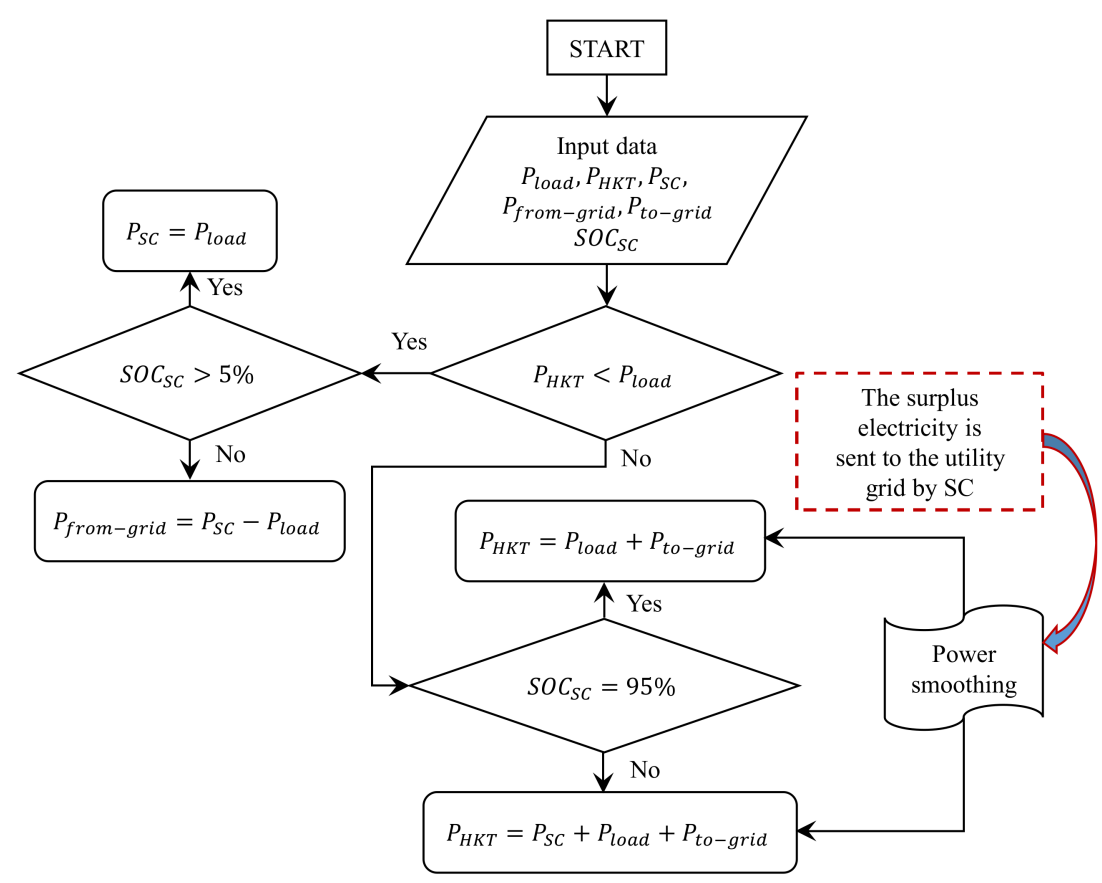

Figure 6. Explanatory algorithm of the proposed energy control. 
State 1:

If the renewable power is less than the power of the load $\left(P_{H K T}<P_{\text {load }}\right)$, the algorithm tests the state of charge of the SC $\left(S O C_{S C}>5 \%\right.$ ). If it is greater than $5 \%$ (minimum value to start charging), it means that the SC can supply the load $\left(P_{S C}=P_{l o a d}\right)$.

State 2:

If the renewable power is less than the power of the load $\left(P_{H K T}<P_{\text {load }}\right)$, the algorithm tests the state of charge of the SC $\left(S O C_{S C}>5 \%\right)$. If it is not greater than $5 \%$ (minimum value to start charging [29]), then there is unmet load and must be purchased electricity from the utility grid; at the same time, the SC is charged $\left(P_{\text {from-grid }}=P_{S C}-P_{\text {load }}\right)$.

State 3:

If the output power of HKT is higher than the electric demand $\left(P_{H K T} \geq P_{\text {load }}\right)$, the algorithm tests the SOC in the SC (SOC SC $=95 \%)$; if fully charged, HKT has priority to supply demand, and the surplus electricity is sent to the utility grid $\left(P_{H K T}=P_{\text {load }}+P_{t o-g r i d}\right)$.

State 4:

If the output power of HKT is higher than the electric demand $\left(P_{H K T} \geq P_{\text {load }}\right)$, the algorithm tests the SOC in the SC $\left(S O C_{S C}=95 \%\right)$; if SC is not fully charged, HKT has priority to supply demand, and the surplus electricity is sent to the utility grid and SC $\left(P_{H K T}=P_{S C}+P_{\text {load }}+P_{\text {to-grid }}\right)$.

\subsection{Power Smoothing}

Power smoothing is performed by using the SC to absorb the power peaks produced by HKT and the load. In a heuristic way, the same power of the SC and HKT (5 kW) was dimensioned. The power-smoothing equations are presented below.

When the energy flow goes from HKT to the utility grid, the surplus electricity contains peaks that must first be absorbed by SC before reaching the grid. Equation (1) represents this state.

$$
P_{\text {to-grid }}=P_{H K T}-P_{S C}
$$

If the power flow goes from the utility grid to the prosumers, the SC must smooth the power peaks required by the EV and some appliances; this state is represented by Equation (2).

$$
P_{\text {from-grid }}=P_{S C}-P_{\text {load }}
$$

\subsection{Mathematical Modeling}

\subsubsection{HKT Modeling}

The power output of a hydrokinetic turbine $\left(P_{H K T}\right)$ is expressed as Equation (3) [31].

$$
P_{H K T}=\frac{1}{2} \cdot \rho_{\omega} \cdot A_{H K T} \cdot V_{r}^{3} \cdot C_{p} \cdot \eta_{H K T}
$$

where $\rho_{\omega}$ represents the density of water, $A_{H K T}$ is the cross-sectional area of the HKT, $V_{r}$ is the river speed, $C_{p}$ is the power coefficient of HKT and $\eta_{H K T}$ is the efficiency of HKT.

Depending on the model, the HKT provides electrical power within certain river speed limits, as stated the Equation (4).

$$
V_{r-\text { cut in }}<V_{r}<V_{r-\text { cut off }}
$$

where $V_{r-c u t}$ in is the minimum operating river speed of HKT, and $V_{r-c u t ~ o f f}$ is the maximum operating river speed of HKT. 


\subsubsection{SC Modeling}

The energy of an SC ( $E_{S C}$ in Joules) is calculated with Equation (5) [32].

$$
E_{S C}=\frac{1}{2} \cdot C_{S C} \cdot V_{S C}^{2}
$$

where $C_{S C}$ is the capacitance of the SC, and $V_{S C}$ is the potential difference between the final voltage and the initial voltage of the $\mathrm{SC}$ in each state of charge.

The efficiency of the SC is calculated with Equation (6) [5].

$$
\eta_{S C}=\frac{P_{S C}}{P_{S C}+P_{S C}^{W}} \cdot 100 \%
$$

where $P_{S C}^{W}$ is the power loss in an SC.

The state of charge (SOC) of the supercapacitor is proportional to the voltage of the equipment, and it can be calculated with Equation (7) [16].

$$
S O C_{S C}=\frac{V_{S C}-V_{S C \min }}{V_{S C \max }-V_{S C \min }} \cdot 100 \%
$$

where $V_{S C \max }$ and $V_{S C \min }$ represent the maximum and minimum voltage of the SC respectively during the instantaneous operation of the SC.

SCs in laboratory tests show a different behavior than computer simulations: the minimum state of charge that they are capable of reaching is 5\% and the maximum is $95 \%$. This has been demonstrated by real tests in the laboratory of the University of Cuenca, Ecuador [32]. This restriction is expressed with Equation (8).

$$
5 \%<S O C_{S C}<95 \%
$$

In addition, the following voltage and current restrictions must be met:

$$
\begin{gathered}
V_{S C \text { min }}<V_{S C}<V_{S C \text { max }} \\
I_{S \text { C max }}^{\text {ch }}<I_{S C}<I_{S C \text { max }}^{\text {Disch }}
\end{gathered}
$$

where $I_{S C \text { max }}^{C H}$ and $I_{S C \text { max }}^{\text {Disch }}$ are the maximum charge and discharge current allowed in an SC.

\subsubsection{Utility Grid Modeling}

The utility grid has been considered an infinite power shunt bus connected with the proposed renewable system. The utility grid parameters are as follows: electrical power $=$ $100 e^{10} \mathrm{VA}$, voltage $=3.3 \mathrm{kV}$, frequency $=60 \mathrm{~Hz}$ and $\mathrm{X} / \mathrm{R}$ ratio $=7$.

The instantaneous power $(\mathrm{kW})$ exchanged between the utility grind and prosumers has upper limits, as expressed in Equations (11) and (12).

$$
\begin{gathered}
P_{\text {to-grid }}<P_{\text {maxgrid }} \\
P_{\text {from-grid }}<P_{\text {maxgrid }}
\end{gathered}
$$

where $P_{\max g r i d}$ expresses the maximum electrical power exchange between the utility grid and the residential load.

The purchase and sale of electricity to/from the utility grid is not possible simultaneously; this restriction is expressed with Equation (13).

$$
P_{\text {from-grid }}^{t}+P_{\text {to-grid }}^{t} \leq 1
$$

where the $P_{\text {from-grid }}^{t}$ binary variable $=1$ if the utility grid supplies power to the prosumer at time $t$; and the $P_{t o-g r i d}^{t}$ binary variable $=1$ if surplus electricity is sent to the grid at time, $t$. 
The restrictions of Equations (14) and (15) represent grid power outages during time, $t$; that is, it simulates the grid unavailability [33].

$$
\begin{gathered}
P_{\text {from-grid }}^{t}=0 \\
P_{\text {to-grid }}^{t}=0
\end{gathered}
$$

\section{Results}

\subsection{Electric Flow Balance}

The result of the energy balance is shown in Figure 7. The daily common behavior with sampling every hour is seen in Figure 7d. The HKT output power is relatively constant during the day; to cover the power peaks produced by customers' load (residential + EV), the SC provides output power. By increasing the sampling (30 min intervals), as shown in Figure $7 c$, the power fluctuations with respect to the previous case are evident; this is seen even more so in Figure $7 \mathrm{~b}$, where the sampling rate is performed at 15-min intervals. It is noticeable that the highest peak load in this case presents two maximum values, which in the two previous cases presented a single maximum value. Then, when the sampling rate is performed at time intervals every minute, the stochastic behavior more closely resembles a real system, e.g., load peaks have various maximum and minimum values where the SC supplies them. The random behavior of the HKT power output varies considerably every minute.

(a)

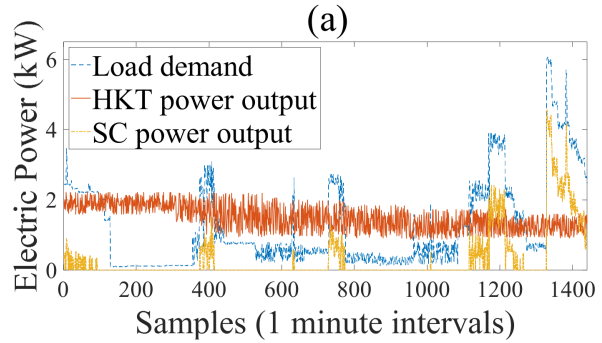

(c)

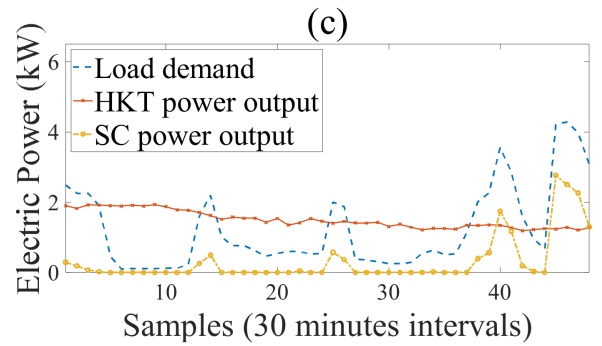

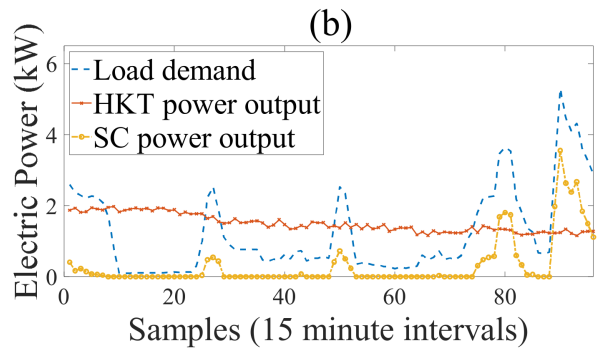

(d)

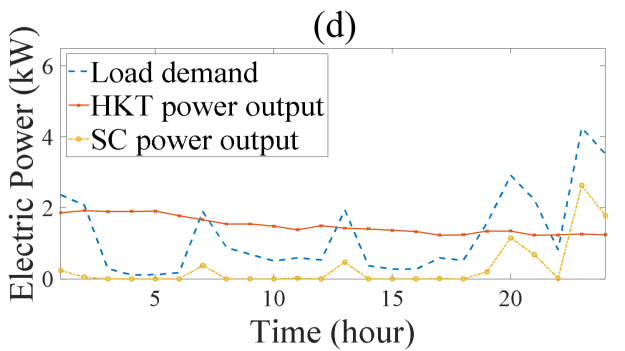

Figure 7. Energy balance of the renewable system connected to the grid. Data sampling at different time intervals: (a) $1 \mathrm{~min},(\mathbf{b}) 15 \mathrm{~min}$, (c) $30 \mathrm{~min}$ and (d) every hour (60 min).

The relative error when measuring the data at different sampling intervals is shown in Table 1. As the time interval is longer, the demand consumption, the energy generated by HKT and the output energy from SC are greater. Relative errors are recorded up to $9 \%$ with respect to the daily SC output energy when comparing the sampling interval every $1 \mathrm{~min}$ against $60 \mathrm{~min}$. 
Table 1. Relative error of data measurements at different sampling intervals.

\begin{tabular}{cccc}
\hline $\begin{array}{c}\text { Data Sampling } \\
\text { Intervals }\end{array}$ & $\begin{array}{c}\text { Load Demand } \\
\text { (kWh/Day) }\end{array}$ & $\begin{array}{c}\text { HKT Power Output } \\
\text { (kWh/Day) }\end{array}$ & $\begin{array}{c}\text { SC Power Output } \\
\text { (kWh/Day) }\end{array}$ \\
\hline 1 & 27.56 & 34.97 & 6.89 \\
15 & 28.02 & 35.02 & 6.92 \\
30 & 28.96 & 35.36 & 7.51 \\
60 & 29.52 & 36.06 & 7.63 \\
\hline
\end{tabular}

On the other hand, the SC supplies the short-time power peaks, and its high power density allows it to have a fast response; the load states for different data sampling are shown in Figure 8. The variations in output power of SC are more noticeable in Figure 8a. If the sampling rate is reduced, the peaks tend to be flattened. Figure $8 \mathrm{~d}$ shows the common behavior of the SC but not real.

(a)

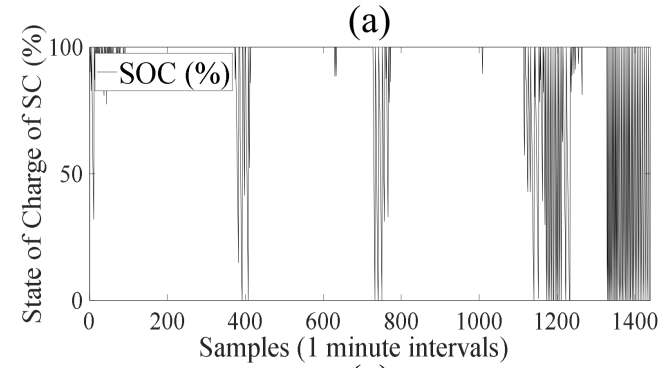

(c)

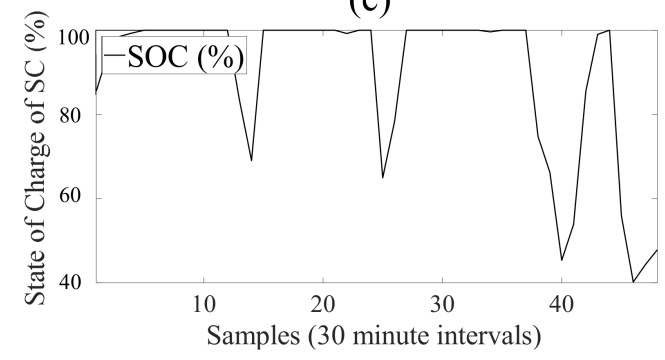

(b)

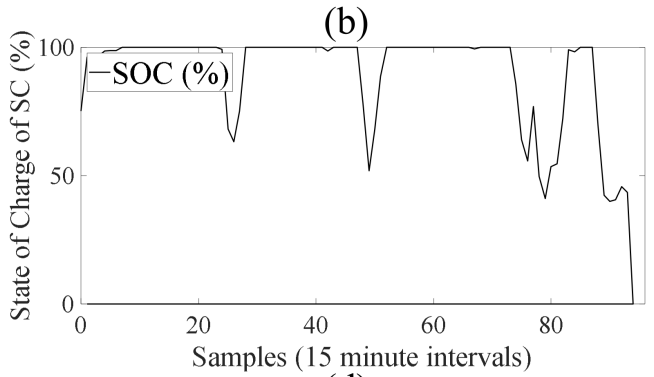

(d)

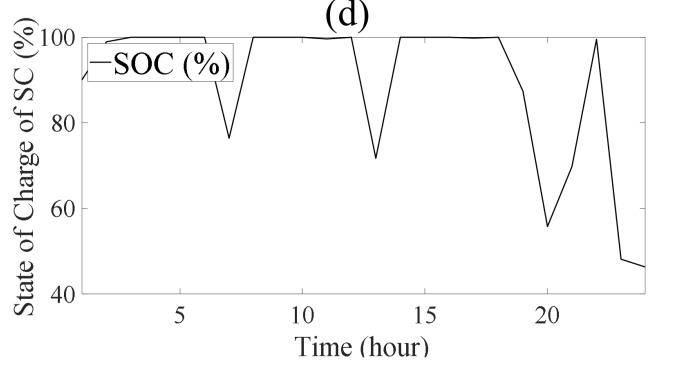

Figure 8. State of charge in SC. Data sampling at different time intervals: (a) $1 \mathrm{~min}$, (b) $15 \mathrm{~min}$, (c) $30 \mathrm{~min}$ and (d) every hour.

\subsection{Power Smoothing and Self-Consumption Results}

The electricity purchased from the utility grid without an HKT/SC system depends on the load profile of the prosumers, which can have various peaks produced by some appliances and the EV. When considering these phenomena on a large scale, they can produce instability in the utility grid. Thus, smoothing out power peaks with an SC is a promising alternative. Figure 9 shows the comparison between an HKT/Grid and HKT/SC/Grid system; the reduction of power peaks purchased from the utility grid is significant, and the SC smoothed out most of the demand fluctuations. Similar to the previous cases, the higher data sampling rate shows the real behavior of the system; the SC responds appropriately to the fast electric power fields.

The sold electricity to the utility grid must be smoothed without harming the economic income it can offer, in contrast to the electricity purchased from the grid, which must be as low as possible to increase self-consumption. In this case, all excess electricity must be sold to the utility grid before that in order to avoid stability problems; the power peaks must be absorbed by an SC if it is discharged. Figure 10 shows the result of the power smoothing by the SC in the scheme proposed in this paper. The behavior between different data samples is similar to the previous cases, which is why the case of Figure 10a is highlighted. The HKT/Grid system (blue line) sends energy with high fluctuations to the grid; by including an SC, these variations decrease drastically without reducing the net energy sold. This type of proposed energy control could encourage prosumers to use HKT/SC on the grid. 
(a)

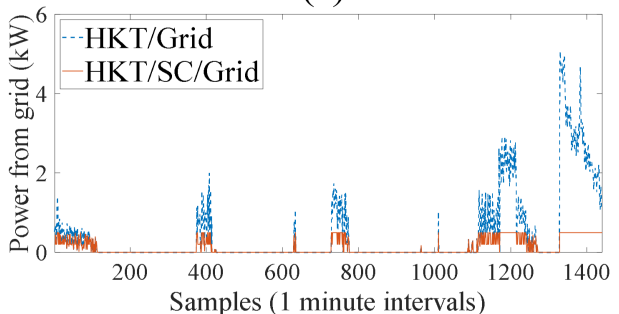

(c)

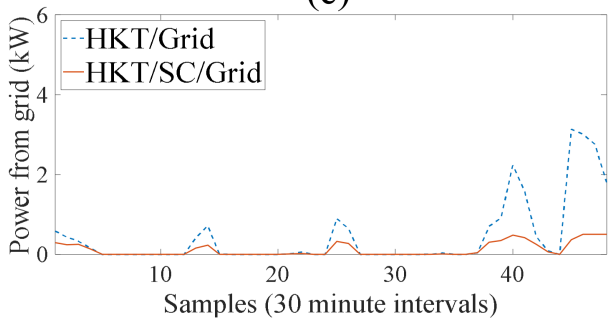

(b)

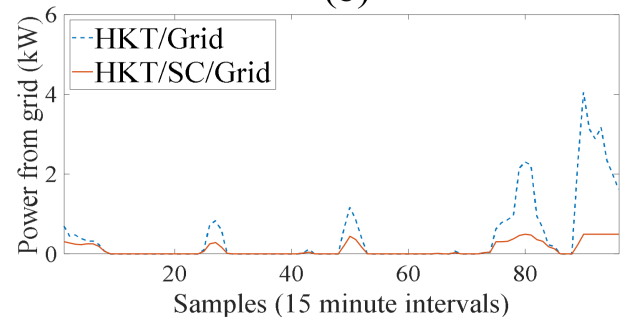

(d)

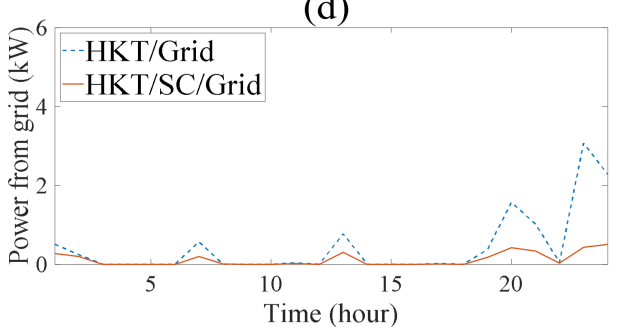

Figure 9. Electric power from the utility grid in case of unmet load by HKT. Data sampling at different time intervals: (a) $1 \mathrm{~min}$, (b) $15 \mathrm{~min}$, (c) $30 \mathrm{~min}$ and (d) every hour.

(a)

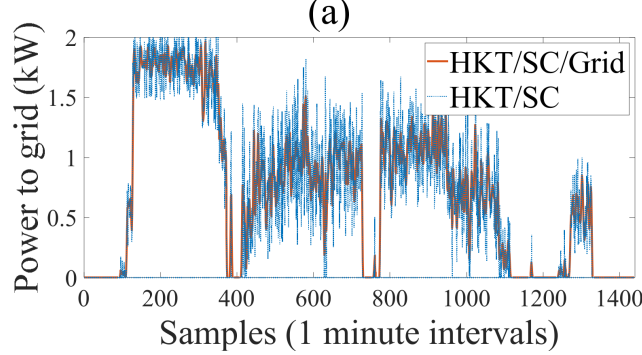

(c)

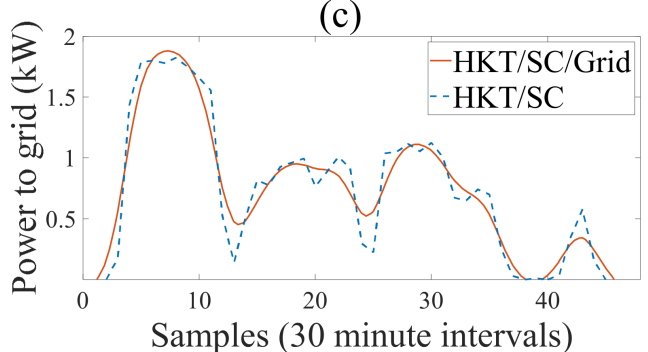

(b)

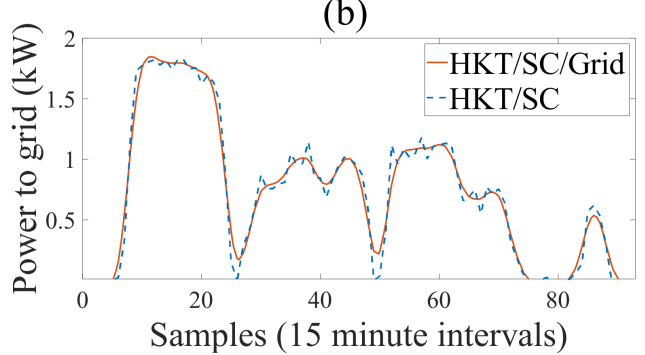

(d)

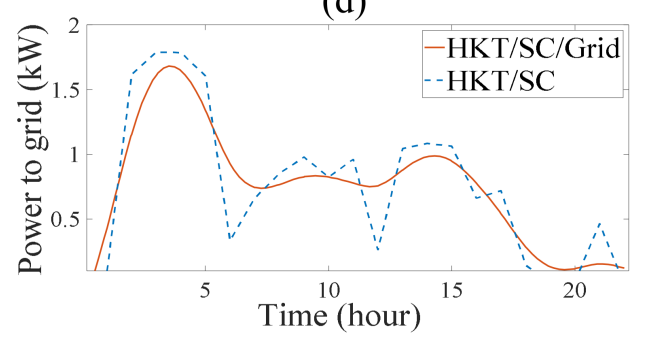

Figure 10. Electricity surplus peaks smoothed and sent to the grid. Data sampling at different time intervals: (a) $1 \mathrm{~min},(\mathbf{b}) 15 \mathrm{~min},(\mathbf{c}) 30 \mathrm{~min}$ and (d) every hour.

The data measured at different time intervals reveal the errors with respect to the real behavior of the system. The short-time power peaks measured at small sampling intervals cause an increase in the energy purchased and sent to the utility grid with respect to larger samples intervals; this difference is based on the averaging of data at larger intervals, which causes an inaccurate dimensioning of renewable sources or the expected cost of sending and purchase electricity to the utility grid.

Table 2 shows the following results, without considering the SC as an energy storage system. The energy purchased from the utility grid measured at 1 min intervals is 1.18 times greater than measured every $60 \mathrm{~min}$; the energy sold is 1.21 times greater with respect to the same sampling interval. When considering the SC, the difference in the energy purchased and sold to the utility grid is 1.72 and 1.20 times greater when measuring samples every minute, rather than every $60 \mathrm{~min}$, respectively. 
Table 2. Relative error of data measurements, self-consumption considering SC.

\begin{tabular}{ccccc}
\hline $\begin{array}{c}\text { Data Sampling } \\
\text { Intervals }\end{array}$ & $\begin{array}{c}\text { Energy from } \\
\text { Grid without } \\
\text { SC (kWh/Day) }\end{array}$ & $\begin{array}{c}\text { Energy Sent to } \\
\text { Grid without } \\
\text { SC (kWh/Day) }\end{array}$ & $\begin{array}{c}\text { Energy from } \\
\text { Grid with SC } \\
\text { (kWh/Day) }\end{array}$ & $\begin{array}{c}\text { Energy Sent to } \\
\text { Grid with SC } \\
\text { (kWh/Day) }\end{array}$ \\
\hline 1 & 12.36 & 20.51 & 4.96 & 20.53 \\
15 & 11.95 & 19.24 & 3.52 & 19.27 \\
30 & 11.1 & 18.37 & 3.05 & 18.39 \\
60 & 10.5 & 17.03 & 2.87 & 17.04 \\
\hline
\end{tabular}

A method of measuring self-consumption is through the reduction of electricity purchased from the utility grid. Table 3 shows that self-consumption can be increased to $73 \%$ with an SC. This result is high because the HKT energy cannot cover certain demand peaks without the SC; therefore, energy must be purchased from the utility grid, thus reducing self-consumption. In addition, the energy sent to the grid also increases when using an SC; this behavior is due to the fact that, in certain cases, the SC stores a surplus of electricity to send to the utility grid.

Table 3. Increase in self-consumption when using SC in the HKT/On grid renewable system.

\begin{tabular}{ccc}
\hline Data Sampling Intervals & $\begin{array}{c}\text { Increase in } \\
\text { Self-Consumption (\%) }\end{array}$ & $\begin{array}{c}\text { Increase in Electricity Send } \\
\text { to Grid (\%) }\end{array}$ \\
\hline 1 & 60 & 0.10 \\
15 & 71 & 0.16 \\
30 & 73 & 0.11 \\
60 & 73 & 0.06 \\
\hline
\end{tabular}

\subsection{Economic Results}

According to Reference [34], the price of electricity for the residential sector in Ecuador is $0.095 \mathrm{USD} / \mathrm{kWh}$. The Feed-in Tariff (FIT) in Ecuador was established through Regulation Coded No. CONELEC 001/13, and the same as was repealed in June 2016. In this regulation no price was contemplated for solar energy photovoltaic or hydrokinetic energy, noting a strong deficiency for the incorporation of this type of renewable energy, to have a reference, and in a similar way a cost of $0.0658 \mathrm{USD} / \mathrm{kWh}$ has been contemplated for hydroelectric plants of up to $5 \mathrm{MW}$ [35], current FIT rate and used in this paper. According to the data presented in Table 2, the USD/day cost of purchased and selling energy to the grid was calculated; the results are shown in Table 4. It is important to mention that the time interval used by the energy meters used by the energy supplier is hourly.

Table 4. Daily cost of energy to/from the utility grid.

\begin{tabular}{ccccc}
\hline $\begin{array}{c}\text { Data Sampling } \\
\text { Intervals }\end{array}$ & $\begin{array}{c}\text { Cost of Energy } \\
\text { from Grid } \\
\text { without SC } \\
\text { (USD/Day) }\end{array}$ & $\begin{array}{c}\text { Cost of Energy } \\
\text { Send to Grid } \\
\text { without SC } \\
\text { (USD/Day) }\end{array}$ & $\begin{array}{c}\text { Cost of Energy } \\
\text { from Grid with } \\
\text { SC (USD/Day) }\end{array}$ & $\begin{array}{c}\text { Cost of Energy } \\
\text { Send to Grid } \\
\text { with SC } \\
\text { (USD/Day) }\end{array}$ \\
\hline 1 & 1.17 & 1.34 & 0.47 & 1.35 \\
15 & 1.13 & 1.26 & 0.33 & 1.26 \\
30 & 1.05 & 1.20 & 0.28 & 1.21 \\
60 & 0.99 & 1.12 & 0.27 & 1.12 \\
\hline
\end{tabular}

Based on the results with data intervals every $1 \mathrm{~min}$, by using SC, the system saves $0.7 \mathrm{USD} /$ day and up to $256 \mathrm{USD} /$ year in the purchase of electricity from the grid and increases the costs of selling electricity to the grid by $0.1 \mathrm{USD} /$ day. These long-term results could represent a significant profit, causing the payback time of the project to be considerably reduced. 
The capital cost of each 56 V, 130F SC Maxwell used in this paper is 1334 (USD/unit), and the replacement cost is 250 (USD/unit), considering a life expectancy of 12 years, and the total project of 25 years. To reach $5 \mathrm{MW}$ of capacity, the cost of adding $30 \mathrm{SC}$ units is 40,520 USD [18].

\section{Concluding Remarks}

In this paper, a feasibility study of a renewable HKT/SC/Grid system was presented and several data sampling intervals were analyzed (1, 15, 30 and $60 \mathrm{~min})$. The proposed energy control allows us to increase the self-consumption of prosumers and smoothing the power peaks produced by some electrical appliances and an EV connected to a residential load in Southern Ecuador. Real data were used, and the results of the study are as follows:

When comparing the results at different sampling intervals, measurement errors were observed in short power peaks that were detected at intervals every $1 \mathrm{~min}$ and not at $60 \mathrm{~min}$. Relative errors are recorded up to $9 \%$ with respect to the daily SC output energy when comparing the sampling interval every $1 \mathrm{~min}$ against $60 \mathrm{~min}$.

Errors were also observed in the energy to/from the utility grid; the energy purchased from the grid measured at intervals of $1 \mathrm{~min}$ is 1.18 times greater than that measured every $60 \mathrm{~min}$ if an SC is not considered and 1.72 times if SC is considered. Regarding the energy sent to the grid, when measured every $1 \mathrm{~min}$, it is 1.21 times greater than when measuring it every $60 \mathrm{~min}$, considering an SC, and 1.20 times without considering the SC. In summary, when measuring the data at a higher sampling rate, the energy to/from the utility is higher due to the power peaks that are detected in high resolution measurements.

If an SC is considered, the system saves $59.87 \%$ of energy purchased from the utility grid each day $(7.4 \mathrm{kWh} /$ day) when considering sampling intervals similar to the real behavior of the system (samples each $1 \mathrm{~min}$ ). Moreover, the use of SC causes an increase in the electricity sent to the grid by $20 \mathrm{Wh} /$ day.

On the other hand, the self-consumption of electricity of the prosumers can increase to $73 \%$, considering the SC in the system under data sampling every 30 and $60 \mathrm{~min}$. If the sampling rate increases (time interval reduces), the increase in self-consumption is slightly less; for sampling intervals every $15 \mathrm{~min}$, the increase is $70 \%$, and every $1 \mathrm{~min}$ is $60 \%$, so these are still promising values.

Finally, the use of an SC can reduce the purchase of electricity from the grid by 256 USD/year compared to an HKT system without SC, and it can increase the cost of sale by up to $0.1 \mathrm{USD} /$ day. According to these data, the HKT/SC/Grid system would save up to $489.1 \mathrm{USD} /$ year in the cost of purchasing electricity from the grid and would increase by 492.75 USD/year for the sale of electricity to the utility grid if the data sample is measured from $1 \mathrm{~min}$ intervals. According to the results obtained, it is recommended to use energy meters with sampling intervals of $1 \mathrm{~min}$, since it shows a more realistic data behavior than the hourly data.

Author Contributions: Conceptualization, P.A.; data curation, P.A.; formal analysis, P.A. and M.T.-V.; funding acquisition, M.T.-V. and F.J.; investigation, P.A.; methodology, P.A. and M.T.-V.; project administration, M.T.-V. and F.J.; resources, M.T.-V. and F.J.; software, P.A. and F.J.; supervision, M.T.-V. and F.J.; validation, P.A. and M.T.-V.; visualization, M.T.-V. and F.J.; writing-original draft, P.A. and M.T.-V.; writing-review and editing, F.J. All authors have read and agreed to the published version of the manuscript.

Funding: This research received no external funding.

Conflicts of Interest: The authors declare no conflict of interest.

\section{References}

1. Ullah, S.; Haidar, A.M.A.; Hoole, P.; Zen, H.; Ahfock, T. The current state of Distributed Renewable Generation, challenges of interconnection and opportunities for energy conversion based DC microgrids. J. Clean. Prod. 2020, 273, 122777. [CrossRef]

2. Xu, Z.; Liu, H.; Sun, H.; Ge, S.; Wang, C. Power supply capability evaluation of distribution systems with distributed generations under differentiated reliability constraints. Int. J. Electr. Power Energy Syst. 2022, 134, 107344. [CrossRef] 
3. Zeynali, S.; Rostami, N.; Feyzi, M.R. Multi-objective optimal short-term planning of renewable distributed generations and capacitor banks in power system considering different uncertainties including plug-in electric vehicles. Int. J. Electr. Power Energy Syst. 2020, 119, 105885. [CrossRef]

4. Jaszczur, M.; Hassan, Q.; Palej, P.; Abdulateef, J. Multi-Objective optimisation of a micro-grid hybrid power system for household application. Energy 2020, 202, 117738. [CrossRef]

5. Panhwar, I.H.; Ahmed, K.; Seyedmahmoudian, M.; Stojcevski, A.; Horan, B.; Mekhilef, S.; Aslam, A.; Asghar, M. Mitigating Power Fluctuations for Energy Storage in Wind Energy Conversion System Using Supercapacitors. IEEE Access. 2020, 8, 189747-189760. [CrossRef]

6. Jayalakshmi, N.S.; Gaonkar, D.N. A new control method to mitigate power fluctuations for grid integrated PV/wind hybrid power system using ultracapacitors. Int. J. Emerg. Electr. Power Syst. 2016, 17, 451-461. [CrossRef]

7. Dizqah, A.M.; Maheri, A.; Busawon, K.; Kamjoo, A. A Multivariable Optimal Energy Management Strategy for Standalone DC Microgrids. IEEE Trans. Power Syst. 2015, 30, 2278-2287. [CrossRef]

8. Abbassi, A.; Dami, M.A.; Jemli, M. A statistical approach for hybrid energy storage system sizing based on capacity distributions in an autonomous PV/Wind power generation system. Renew. Energy 2017, 103, 81-93. [CrossRef]

9. Esmaili, A.; Novakovic, B.; Nasiri, A.; Abdel-Baqi, O. A hybrid system of li-ion capacitors and flow battery for dynamic wind energy support. IEEE Trans. Ind. Appl. 2013, 49, 1649-1657. [CrossRef]

10. Miñambres-Marcos, V.M.; Guerrero-Martínez, M.Á.; Barrero-González, F.; Milanés-Montero, M.I. A grid connected photovoltaic inverter with battery-supercapacitor hybrid energy storage. Sensors 2017, 17, 1856. [CrossRef]

11. Khalid, M. A Review on the Selected Applications of Battery-Supercapacitor Hybrid Energy Storage Systems for Microgrids. Energies 2019, 12, 4559. [CrossRef]

12. Abbey, C.; Joos, G. Supercapacitor Energy Storage for Wind Energy Applications. IEEE Trans. Ind. Appl. 2007, 43, 769-776. [CrossRef]

13. Qu, L.; Qiao, W. Constant Power Control of DFIG Wind Turbines with Supercapacitor Energy Storage. IEEE Trans. Ind. Appl. 2011, 47, 359-367. [CrossRef]

14. Tani, A.; Camara, M.B.; Dakyo, B. Energy Management in the Decentralized Generation Systems Based on Renewable EnergyUltracapacitors and Battery to Compensate the Wind/Load Power Fluctuations. IEEE Trans. Ind. Appl. 2015, 51, 1817-1827. [CrossRef]

15. González, L.G.; Chacon, R.; Delgado, B.; Benavides, D.; Espinoza, J. Study of Energy Compensation Techniques in Photovoltaic Solar Systems with the Use of Supercapacitors in Low-Voltage Networks. Energies 2020, 13, 3755. [CrossRef]

16. JHernández, C.; Gomez-Gonzalez, M.; Sanchez-Sutil, F.; Jurado, F. Optimization of battery/supercapacitor-based photovoltaic household-prosumers providing self-consumption and frequency containment reserve as influenced by temporal data granularity. J. Energy Storage 2021, 36, 102366. [CrossRef]

17. Schmid, F.; Winzer, J.; Pasemann, A.; Behrendt, F. An open-source modeling tool for multi-objective optimization of renewable nano/micro-off-grid power supply system: Influence of temporal resolution, simulation period, and location. Energy 2021, 219, 119545. [CrossRef]

18. Jaszczur, M.; Hassan, Q. An optimisation and sizing of photovoltaic system with supercapacitor for improving self-consumption. Appl. Energy 2020, 279, 115776. [CrossRef]

19. Linssen, J.; Stenzel, P.; Fleer, J. Techno-economic analysis of photovoltaic battery systems and the influence of different consumer load profiles. Appl. Energy 2017, 185, 2019-2025. [CrossRef]

20. Hassan, Q. Evaluation and optimization of off-grid and on-grid photovoltaic power system for typical household electrification. Renew. Energy 2021, 164, 375-390. [CrossRef]

21. Jaszczur, M.; Hassan, Q.; Abdulateef, A.M.; Abdulateef, J. Assessing the temporal load resolution effect on the photovoltaic energy flows and self-consumption. Renew. Energy 2021, 169, 1077-1090. [CrossRef]

22. Claessens, B.; Engels, J.; Deconinck, G. Combined stochastic optimization of frequency control and self-consumption with a battery. IEEE Trans. Smart Grid. 2019, 10, 1971-1981. [CrossRef]

23. Zhou, Z.; Benbouzid, M.; Charpentier, J.F.; Scuiller, F.; Tang, T. A review of energy storage technologies for marine current energy systems. Renew. Sustain. Energy Rev. 2013, 18, 390-400. [CrossRef]

24. Chen, W.; Adnanses, A.K.; Hansen, J.F.; Lindtjorn, J.O.; Tang, T. Super-capacitors based hybrid converter in marine electric propulsion system. XIX Int. Conf. Electr. Mach. -ICEM 2010, 2010, 1-6.

25. John, B.; Thomas, R.N.; Varghese, J. Integration of hydrokinetic turbine-PV-battery standalone system for tropical climate condition. Renew. Energy 2020, 149, 361-373. [CrossRef]

26. Baruah, A.; Basu, M.; Amuley, D. Modeling of an autonomous hybrid renewable energy system for electrification of a township: A case study for Sikkim, India. Renew. Sustain. Energy Rev. 2021, 135, 110158. [CrossRef]

27. John, B.; Varghese, J. Sizing and techno-economic analysis of hydrokinetic turbine based standalone hybrid energy systems. Energy 2021, 221, 119717. [CrossRef]

28. Khan, J.; Bhuyan, G.; Moshref, A. Potential Opportunities and Differences Associated with Integration of Ocean Wave and Marine Current Energy Plants in Comparison to Wind Energy. 2009. Available online: https://hal.archives-ouvertes.fr/hal-01265985 / document (accessed on 10 October 2021). 
29. Espinoza, J.L.; Gonzalez, L.G.; Sempertegui, R. Micro grid laboratory as a tool for research on non-conventional energy sources in Ecuador. In Proceedings of the 2017 IEEE International Autumn Meeting on Power, Electronics and Computing, Ixtapa, Mexico, 8-10 November 2017; pp. 1-7. [CrossRef]

30. National Institute of Meteorology and Hydrology_INAMHI. Available online: http:/ /186.42.174.236/InamhiEmas/ (accessed on 20 August 2019).

31. Cano, A.; Arévalo, P.; Jurado, F. Energy analysis and techno-economic assessment of a hybrid PV/HKT/BAT system using biomass gasifier: Cuenca-Ecuador case study. Energy 2020, 202, 117727. [CrossRef]

32. Arévalo, P.; Cano, A.; Benavides, J.; Jurado, F. Feasibility study of a renewable system (PV/HKT/GB) for hybrid tramway based on fuel cell and super capacitor. IET Renew. Power Gener. 2021, 15, 491-503. [CrossRef]

33. Tostado-Véliz, M.; Icaza-Alvarez, D.; Jurado, F. A novel methodology for optimal sizing photovoltaic-battery systems in smart homes considering grid outages and demand response. Renew. Energy 2021, 170, 884-896. [CrossRef]

34. Public Electricity Service of Ecuador, Tariff Schedule for Electric Distribution Companies. Available online: https://www. regulacionelectrica.gob.ec/wp-content/uploads/downloads/2019/07/P-Tarifario-SPEE-2019_Codif.pdf (accessed on 30 September 2021).

35. Munoz-Vixhnay, J.P.; Rojas-Moncayo, M.V.; Barreto-Calle, C.R. Incentive Pertaining to Energy the Generation Distributed in Ecuador. Ingenius. Rev. Cienc. y Tecnol. 2018, 19, 60-68. Available online: http://scielo.senescyt.gob.ec/scielo.php?script=sci_ abstract\&pid=S1390-860X2018000100060\&lng=es\&nrm=iso\&tlng=en (accessed on 10 June 2021). 